\title{
Pengelolaan Sampah Di Daya Tarik Wisata Pantai Candikusuma, Desa Candikusuma, Kecamatan Melaya, Kabupaten Jembrana
}

Made Bagus Megawana,1, Ida Bagus Suryawana,2

1madebagus.mbmb@gmail.com,2idabagussuryawan@unud.ac.id

aProgram Studi Sarjana DestinasiPariwisata, FakultasPariwisata,UniversitasUdayana, Jl. Dr. R. Goris, Denpasar, Bali 80232 Indonesia

\section{Abstract}

This research was conducted to find out what kind of waste management is in the tourist attraction of Candikusuma Beach and how much participation and involvment of society in it. Garbage now becomes a crucial problem so it needs to be identified more about it's management. Waste is a challenge in the implementation of tourism activities. Rubbish need to be addressed in maintaining Cleanliness (Kebersihan) and Beauty (Keindahan) of tourism attraction as an indicator in the Sapta Pesona. The methods used in this research is descriptive qualitative. The technique of determination of informants used is purposive sampling technique. Data sources used are primary and secondary data sources. Primary data in this research is sourced from direct observation to the research location by means of observation and interviews. While secondary data in this research are the data obtained from the documentation or studies library to complement the primary data from the Locus of the reserch. The results of research indicate that the existing waste management in coastal touristattraction Candikusuma Beach is good, it'sjust the involvement of the community in it has not been maximized and less care about coastal cleanliness, the identification process of this management using $3 R$ process among others Reduce, Reuse Recycle. Origin of waste there is a large portion of it coming from the junk mail from upstream. Although there are still many things thet need to be addressed in order to make the management process better andmaximum.

\section{Keyword : Waste, 3R Process, Society Participation.}

\section{PENDAHULUAN}

Keberadaan pariwisata sebagai salah satu komoditas unggulan dalam pembangunan suatu daerah tentu tidak asing bagi sebagian masyarakat. Pariwisata yang sudah banyak dikenal sebagai sektor terpenting dalam memperkenalkan dan mempromosikan potensi yang dimiliki setiap daerah tentu tidak terlepas dari adanya kerja sama dan sinergitas antara masyarakat dan unsur-unsur lainnya. Dalam menyelenggarakan pariwisata, tentu bukanlah hal yang mudah dimana diperlukannya suatu perencanaan yang matang agar pariwisata yang diselenggarakan dapat survive di zaman yang terus berkembang.

Upaya dalam penyuksesan dan pemaksimalan kegiatan pariwisata, dewasa ini kian gencar dilaksanakan di Provinsi Bali yang terus berbenah dengan adanya perkembangan teknologi dan informasi yang ada. Upaya pemaksimalan tidak hanya diterapkan pada sistem pengelolaan dan pemberdayaan secara internal, namun pemaksimalan juga diterapkan pada sarana dan prasarana yang disesuaikan dengan keinginan pasar. Namun, kegiatan pariwisata Indonesia atau dalam penelitian ini adalah Bali yang mengandalkan alam sebagai daya tariknya, harus mampu menjaga hubungan yang baik dan harmonis dengan alam. Salah satu upaya tersebut yang nyata dilaksanakan oleh Masyarakat Bali adalah penerapan konsep Tri Hita Karana salah satunya yaitu Palemahan yang berarti menjaga hubungan baik antara manusia dan alam dalam memperoleh kebahagiaan. Konsep ini merupakan salah satu lokal genius dari masyarakat Bali yang masih eksis hingga saat ini. Kondisi alam yang tidak terprediksi dan banyaknya bencana yang timbul pula menjadi permasalahan kompleks serta tantangan bagi penyelenggaraan Pariwisata.

Hal ini pula yang menjadi acuan berpikir dalam menyikapi berbagai masalah karena timbulnya ketidak seimbangan alam. Bali dapat belajar dari fenomena alam erupsi Gunung Agung yang mengakibatkan penurunan kunjungan wisatawan yang cukup drastis dan mengakibatkan ekonomi Bali menjadi tergoyah. Salah satu penyikapan permasalahan tersebut yang dilaksanakan oleh Masyarakat Bali adalah dengan terus gencarnya promosi menggunaan \#BaliAman ( \#BaliStillSave) di berbagai media sosial yang ada, dan berhasil menaikkan kembali jumlah kunjungan wisatawan ke Bali dan perekonomian warga kembali stabil. Namun, selain permasalahan tersebut bagaimana dengan permasalahan lainnya? Apakah sudah ada pemaksimalan dan pencarian solusi yang benar dalam permasalahan ini? Permasalahan tersebut 
adalah Permasalahan Sampah. Kesadaran masyarakat yang kurang akan pentingnya menjaga kebersihan lingkungan, mengakibatkan banjir yang membawa begitu banyak sampah dan bermuara di hulu yaitu Pantai. Hal ini pula dapat menjadi permasalahan yang serius bila tidak ditangani dengan bijak dan cerdas.

Tumpukan sampah di bibir pantai dan sekitarnya, ditambah dengan minimnya kesadaran wisatawan dalam membuang sampah pada tempatnya menjadikan Pantai, yang pada awalnya menjadi magnet wisatawan untuk berkunjung dapat menjadi bumerang bagi warga itu sendiri. Salah satu contoh pantai yang terkena permasalahan ini adalah Pantai Candikusuma yang terletak di Desa Candikusuma, Kecamatan Melaya, Kabupaten Jembrana Bali. Menyikapi permasalahn tersebut, perlu adanya solusi yang benar dalam mengatasi masalah sampah di daerah Pantai di Provinsi Bali.

Hal tersebut menjadi menarik untuk diteliti bagaimana dalam mengulas lebih jauh solusi yang baik dalam mengatasi permasalahan sampah, bagaimana mengelola dan bagaimana penjegahannya guna penerapan konsep Pariwisata berkelanjutan. Sehingga peneliti mengambil judul " Pengelolaan Sampah Di Daya Tarik Wisata Pantai Candikusuma, Desa Candikusuma, Kecamatan Melaya, Kabupaten Jembrana, Bali."

\section{Rumusan Masalah}

Adapun rumusan masalah penelitian ini adalah sebagai berikut.

1. Bagaimana kondisi eksisting Daya Tarik Wisata Pantai Candikusuma, Desa Candikusuma, Kecamatan

Melaya, Kabupaten Jembrana?

2. Bagaimana pengelolaan sampah di Daya Tarik Wisata Pantai Candikusuma, Desa Candikusuma, Kecamatan Melaya, Kabupaten Jembrana?

\section{TINJAUAN PUSTAKA}

\subsection{Telaah Penelitian Sebelumnya}

Telaah hasil penelitian sebelumnya merupakan penelitian yang sebelumnya telah dilakukan yang memiliki persamaan maupun perbedaan antara fokus dan lokus. Telaah hasil penelitian sebelumnya bertujuan untuk membandingkan penelitian yang sedang diteliti dengan penelitian yang telah dilakukan.

Penelitian pertama dilakukan oleh Yuni Puspitawati dan Mardwi Rahdriawan pada 2012, dengan judul "Kajian Pengelolaan Sampah Berbasis Masyarakat dengan Konsep 3R (Reduce, Reuse, Recycle) di Kelurahan Larangan Kota Cirebon". Penelitian yang kedua adalah karya Sukma Arida, dengan judul "Krisis Lingkungan Bali dan Peluang Ekowisata". Berdasarkan kedua penelitian tersebut maka sangat relefan dengan penelitian ini, dimana perlu diambil sikap dan solusi yang tepat dengan adanya krisis lahan pantai tersebut, ditambah dengan permasalahan sampahyangada.

\section{2 . Deskripsi Konsep}

Adapun konsep yang digunakan antara lain terdiri dari konsep sampah menurut Kamus Lingkungan Hidup (1994) dan menurut Kamus Lingkungan Hidup (2012), konsep keterlibatan masyarakat dalam pengelolaan sampah menurut Yarianto, (2005).

\section{METODE}

Pendekatan yang digunakan merupakan pendekatan kualitatif. Dalam penelitian ini mengutamakan makna dari informasi yang diperoleh meliputi data kondisi eksisting daya tarik wisata Pantai Candikusuma dan data terkait pengelolaan sampah. Jenis penelitian ini adalah deskriptif kualitatif. Dalam penelitian ini peneliti mengumpulkan data yang kemudian akan diolah dan dihubungkan sehingga mendapatkan fenomena terkait sampah dan pengelolaannya secara utuh. Lokasi penelitian dilaksanakan di Pantai Candikusuma, Desa Candikusuma, Kecamatan Melaya, Kabupaten Jembrana, Provinsi Bali. Pemilihan lokasi penelitian tersebut didasarkan fenomena sampah yang terjadi di Pantai Candikusuma. Adapun teknik pengumpulan data adalah wawancara, observasi, dan dokumentasi. Teknik penentuan informan yang digunakan adalah purposif sampling, dimana peneliti menentukan informan yang disesuaikan dengan struktur sosial saat pengumpulan data dilakukan.
a. Perbekel Desa Candikusuma
b. Kelian Banjar Tirta Kusuma
c. Pokdarwis Desa Candikusuma 
IV. HASIL DAN PEMBAHASAN

4.1. Kondisi Eksisting Daya Tarik Wisata Pantai Candikusuma

\section{A. Kondisi dan Jenis Sampah}

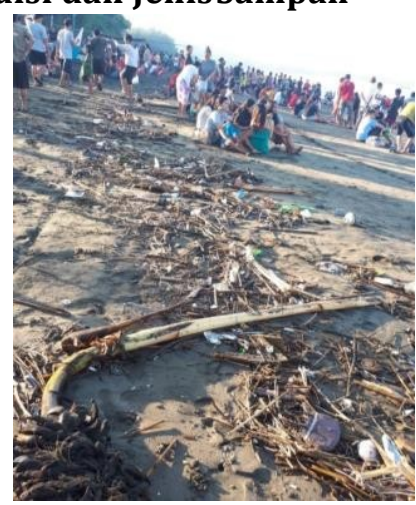

Gambar 1. Kondisi sampah yang ada di Pantai Candikusuma.

Sumber : Hasil Penelitian

Kondisi sampah yang ada di Pantai Candikusuma dapat dikatakan memiliki intensitas yang cukup tinggi dengan jenis sampah yang sangat beragam. Sampah begitu banyak tersebar di pesisir pantai dan daerah sekitaran pantai.Sampah di sekitar pantai sebagian besar didominasi oleh sampah organik seperti ranting pohon, dedaunan, bekas canang, dan sampah yang mudah terurai lainnya, namun sampah anorganik seperti plastik, sandal bekas dan botol minuman juga dapat ditemukan.

\section{B. Asal Sampah}

Menurut pada hasil wawancara bersama Kelian Banjar Tirta Kusuma, Desa Candikusuma, Bapak Sutikno menjelaskan bahwa sampah yang berada di Pantai Candikusuma sebagian besar adalah sampah kiriman yang berasal dari aliran sungai dan bermuara di bibir pantai. Adapun sungai yang terletak tidak jauh dari Pantai Candikusuma adalah Tukad Daya dan Tukad Melaya. Sampah-sampah yang ada di Pantai, walaupun didominasi karena adanya proses kiriman sampah melalui aliran sungai, sampah juga dikarenakan adanya pihakpihak yang tidak bertanggung jawab yang membuang sampah sembarangan di sekitaran Pantai. Sampah- sampah ini memiliki jenis sampah yang berbeda yaitu sampah Anorganik yang secara teknis lebih lama proses penguraiannya.

\section{Kondisi Tempat Pembuangan Sampah (TPS)}

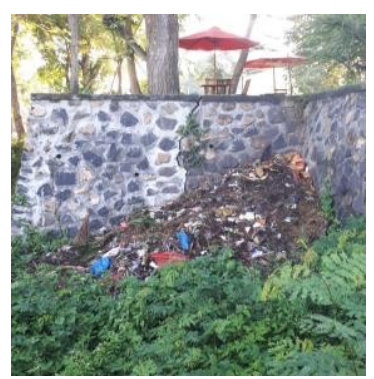

Gambar 2. Tempat Pembuangan Sampah (TPS) liar di lingkungan Pantai Candikususma. Sumber : Hasil Penelitian

Kondisi tempat pembuangan sampah di Pantai Candikusuma masih belum jelas keberadaannya terkecuali tempat sampah.Untuk tempat sampah memang sudah disediakan dari Kabupaten guna sebagai fasilitas pendukung Daya Tarik Pantai Candikusuma.

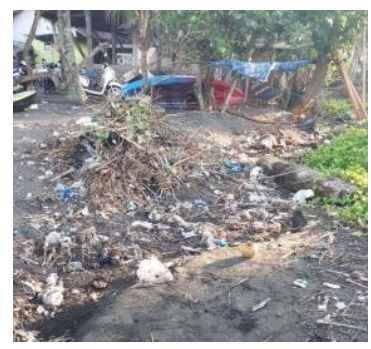

Gambar 3. Tempat Pambuangan Sampah (TPS) liar di dekat pesisir Pantai Candikususma. Sumber : Hasil Penelitian

Karena ketidak jelasan mengenai tempat pembuangan sampah, mengakibatkan banyaknya tempat pembuangan liar di dekat pesisir Pantai Candikusuma.

\section{Respon Masyarakat}

Berdasarkan pada hasil wawancara bersama Kelian Banjar Tirta Kusuma, Desa Candikusuma, Bapak Sutikno menyatakan bahwa respon masyarakat terhadap sampah memang dirasa kurang. Namun ada beberapa kelompok kelompok masyarakat yang peduli terhadap kondisi sampah yang ada. Mereka melakukan kegiatan daur ulang (recycle) sampah-sampah yang ada dan dijadikan 
sebagai barang bernilai ekonomis seperti tas, dompet dan wadah sesaji (Sokasi).

Adapun kelompok-kelompok masyarakat yang melaksanakan kegiatan daur ulang sampah anorganik ini adalah Ibu-Ibu PKK yang tergabung dalam Bank Sampah Amerta Buana dan Pokdarwis Desa Candikusuma.

\subsection{Pengelolaan Sampah dengan Proses $3 R$}

Proses 3R yang dilakukan oleh masyarakat dalam proses pengelolaan sampah yang ada di Desa Candikusuma adalah sebagai berikut:

\section{A. Reuse (Menggunakan Kembali)}

Proses Reuse yang dilakukan adalah menggunakan kembali botol-botol bekas minuman yang sama dan sejenis untuk selanjutnya dimanfaatkan sebagai bahan kemasan produk dari Ibu-Ibu PKK yang tergaung dalam Amerta Buana yaitu produk Jamu yang langsung diproduksi oleh masyarakat. Dari sampah botol yang ada, dipilah dan disortir kembali dan disesuaikan dengan jenis dan ukuran botol yang sama, dibersihkan dan selanjutnya dimanfaatkan kembali menjadi kemasan produk Jamu yang telah diproduksi.

\section{B. Reduce (Mengurangi)}

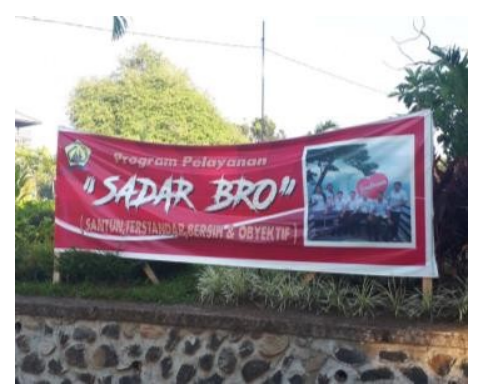

Gambar 4. Spanduk yang berisikan ajakan dalam menjaga kebersihan.

Sumber : Hasil Penelitian

Proses Reduce yang dilakukan masyarakat adalah dengan memberikan pemahaman dan sosialisasi dalam menjaga kebersihan lingkungan, pemahaman mengenai penanganan jenis-jenis sampah meliputi sampah organik dan anorganik, meminimalisir penggunaan plastik yang nantinya akan menjadi sampah, serta mengedukasi masyarakat akan pentingnya Perilaku Hidup
Bersih dan Sehat(PHBS).

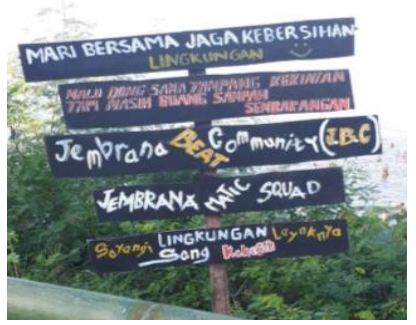

Gambar 5. Plang yang berisikan ajakan dalam menjaga kebersihan.

Sumber : Hasil Penelitian

Upaya riil yang dilakukan oleh pemerintah adalah dengan memasang beberapa spanduk dan plang yang bertujuan untuk mengingatkan pengunjung dalam mengurangi jumlah volume sampah dan menjaga agar lingkungan di Desa dan Pantai Candikusuma tetap bersih.Selain itu, pula diadakan kegiatan Jum'at bersih yang melaksanakan aktifitas kerja bakti membersihkan lingkungan Desa Candikusuma oleh masyarakat, termasuk Pantai Candikusuma. Aktifitas yang dilakukan dalam kegiatan Jum'at bersih berupa mengumpulkan sampah organik maupun anorganik serta menata lingkungan Desa dan Pantai Candikusuma yang dirasa perlu untuk ditata.Namun pada kenyataannya, masih banyak masyarakat yang belum terlibat maupun berpartisipasi dalam melaksanakan kegiatan Jum'at bersih ini, termasuk juga dalam menerapkan upaya pengurangan penggunaan plastik dan mengimplementasikan perilaku hidup bersih dan sehat, masyarakat belum berpartisipasi secara maksimal.

\section{Recycle (Mendaur Ulang)}

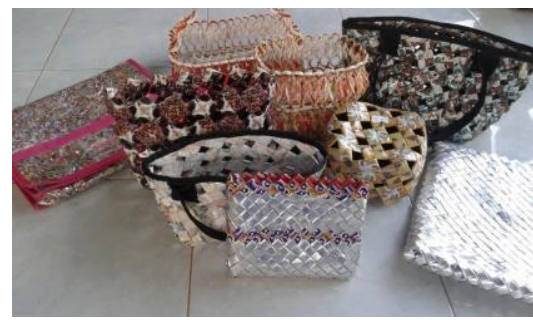

Gambar 6. Produk-produk daur ulang oleh IbuIbu PKK Amerta Buana. Sumber: Hasil Penelitian

Proses mendaur ulang yang dilakukan oleh masyarakat adalah dengan mendaur ulang sampah anorganik menjadi 
produk yang memiliki nilai ekomonis dan dapat berpeluang menjadi komoditas masyarakat lokal Desa Candikusuma. Adapun produk yang telah dibuat seperti tas, wadah sesaji (Sokasi), dompet, tempat minuman, dan lainsebagainya. Sampah yang digunakan biasanya adalah sampah anorganik rumah tangga yang kemudian didaur ulang menjadi barang bernilai jual dipasaran namun untuk proses recycle sampah organik, masyarakat belum terlaksana.

\section{SIMPULAN DAN SARAN}

\section{a. Simpulan}

Dari hasil penelitian dapat disimpulkan bahwa Pantai Candikusuma berdasarkan pada kondisi eksistingnya, memiliki jenis sampah yang berfariatif dan didominasi oleh sampah anorganik yang berasal dari sampah kiriman, dengan kondisi TPS yang kurang memadai, dan respon masyarakat yang kurang. Sedangkan dalam proses pengelolaan 3R, penerapan Recycle dan Reuse sudah dilaksanakan oleh masyarakat dalam mengatasi sampah anorganik, namun untuk sampah organik belum ditangani secara maksimal. Selain itu, dalam proses Reduce,respon masyarakat pula dirasa kurang.

\section{b. Saran}

Berdasarkan pada simpulan diatas, adapun saran yang diberikan kepada Pemerintah dapat memaksimalkan perannya sebagai Fasilitator dan regulator yaitu dengan penambahan fasilitas, penyuluhan, penentuan kebiujakan maupun peraturan yang jelas bagi masyarakat dan pengelola seperti kejelasan Tempat Pembuangan Sampah (TPS) dan tidak melupakan tugasnya sebagai tim pemantau. Sedangkan Masyarakat hendaknya dapat berperaan sebagai partisipator secara aktif dalam pengelolaan sampah terlebih sampah organik karena berdasarkan kondisi lapangan, sampah organik lebih mendominasi dibandingkan dengan sampah anorganik. Peran masyarakat sangatlah penting demi menunjangnya penyelenggaraan aktivitas pariwisata di daya tarik wisata Pantai Candikusuma.

\section{DAFTAR PUSTAKA}

Arida,S. 2006. "Krisis Lingkungan Bali dan peluang ekowisata." INPUT: Jurnal Ekonomi dan Sosial 1.2

Bungin, 2007. Penelitian Kualitataif. Jakarta: PRENADA MEDIA GROUP

Crecwell, Jhon W. 2012. Research Design : Penelitian Kualitatif, Kuantitatif, dan Mixed. Yogyakarta : Pustaka Pelajar

Kusmayadi, Ir., dan Ir. Endar Sugiarto, MM. 2000. Metodologi Penelitian Dalam Bidang Kepariwisataan. Jakarta : PT. Gramedia Pustaka Utama

Moleong, 2012. Metodologi Penelitian Kualitatif. Bandung : PT. Remaja Rosdakarya

Puspitawati, Yuni, \& Mardwi Rahdriawan. 2012. "Kajian Pengelolaan Sampah Berbasis Masyarakat dengan Konsep 3R (Reduce, Reuse,Recycle) di Kelurahan Larangan Kota Cirebon." Jurnal Pembangunan Wilayah \& Kota 8.4, 349359

Sugiono, 2014. Metode Penelitian Kualitatif. Bandung : Linda Karya

Undang-Undang Republik Indonesia Nomor 18 Tahun 2008 Tentang Pengelolaan Sampah

Sumber Lain:

www://desacandikusuma-jembrana.id 
